\title{
A study on the Artistic Characteristics and Practices of Chinese Contemprory Opera
}

\author{
Taking Concert Opera “Ejiamei”as an Example
}

\author{
Caizhen $\mathrm{Li}$ \\ Collage of Literature and Journalism of Sichuan University \\ Chengdu, China
}

\begin{abstract}
In the history of China's nearly 100 years of opera development, through the tireless efforts of Chinese artists, a number of outstanding repertoir have come into the public horizon. The concert opera "Ejiamei", by Sichuan Art Vocational College, with its unique national characteristics, rich cultural connotation and practical art standards, has added a rich and varied part to the history of contemporary Chinese opera.
\end{abstract}

Keywords-Chinese contemporary opera; concert opera; "Ejiamei"

\section{INTRODUCTION}

In China, the art category of opera is a new form of art that has been introduced from the West in the 1930s and 1940s. The theoretical research on this new field produced in China at present is rare in both experience and reference. To this large music genre form the West, Chinese artists are adding many Chinese elements such as opera, folk art, rap, etc., and more specific speaking, ancient music, Kunqu opera, Sichuan opera, Pingtan, etc., and then a new kind of opera with Chinese national characteristics is being formed. In the process of continuous production of new works, the need for theoretical research support became urgent. Today, Chinese opera is in the "flourishing with innovation" environment with all kinds of experimental opera one after another came into being, such as drama opera, chamber opera, little theatre opera, concert opera, national opera and other forms competing with each other. Theory is the guide of practice. Based on this, the theoretical study of Chinese opera is even more important. The concert opera is a comprehensive art form in which the opera is simplified in the form of lighting, costumes, make-up, props and performances on the stage, and is composed of music, dance, art, drama and literature. Its essence is still opera. Compared to ordinary opera, concert opera has subtracted some cumbersome objective factors. With its unique expression of the mood and style, it has attracted many rehearsal groups, especially school groups of all ages.

This article focuses on the contemporary Chinese opera environment. Through the research of the "concert opera" art form of its unique artistic characteristics and application practice and taking the concert opera "Ejiamei" which is by Sichuan Art Vocational College as an example and at the same time combined with the questionnaire survey of certain social groups, this essay summed up the development of Chinese concert opera, its prospects, current problems and the impact on Chinese opera and so on.

\section{ANALYSIS ON THE ARTISTIC CHARACTERISTICS OF CONCERT OPERA "EJIAMEI"}

\section{A. An Overview of the Concert Opera "Ejiamei"}

"Ejiamei" is a concert opera created and rehearsed by the teachers and students in Sichuan Art Vocational College. With the sense of self-awareness and cultural self-confidence as the basis, they adhere to the principle of "do your own job on your own" in the composition and rehearsal of Ejiamei. The main team was composed of the composer Lin Geer, writer Shang Xin, director Wu Huanying, conductor MouLijia, theatre designer Wang Zhibin, lighting designer Liu Zhipeng, costume designer Wu Honggang, modeling designer Xiaobo,etc. Other members of the main team are the experts, professors, as well as 120students from the music department, drama department, and dance department, respectively. The main roles are taken by the young vocal teachers in the music department.

"Ejiamei" is an opera of local theme, local characters and local style. It is an original local comprehensive art work. The operaeulogizes the national harmony and unity, is also the main theme of it. The background is that in ancient times, two peoples, Baima and Dunbu lives beside DabuRiver, Sichuan province. Between Baima and Dunbu people there are grudges of generations. The daughter of the chief of Baima people, Ejiamei, is beautiful, kind and courageous. She successfully resolvesthe rudeness between the tribes and helps them go hand in hand in harmony toward a beautiful future. The language of the play is simple with unified style, compact rhythm with a unique drama style displayed by combining the characteristics of both concert and opera. The play mainly uses a multi-field structure consists of the prelude and five sessions.

\section{B. Language in the Concert Opera "Ejiamei"}

\section{1) Music in "Ejiamei"}

There is no doubt that the musical expression of "Ejiamei" has a strong sense of conflict and it can also meet the current students in their needs of singing technique. In the creation of this opera, the composer Lin Geer combined 
the more mature elements in western music such as creative techniques, performance techniques and creative ideas, which are cleverly integrated into the play. From the development of music motives, to the theme throughout the logic structure of the play and then to the end echo and the combination of Chinese and Western music structure and the use of multi-part music, they all contribute to the music structure of "Ejiamei". National tone, tone of the timely conversion, The singularity, the chanting and the fancy, the narrative factors, the solo, chorus, interspersed chorus and so on, not only embodies the amazing effects of the integration betweenChinese and Western music style, but also make the characters in the opera alive, music dynamic, threedimensional and have more dramatic effects.

"I love you so, my mother-like snow-capped mountains" is one of the main arias in "Ejiamei". It is in the fifth action by Ejiamei solo and it is a very important aria to her characterization. The story takes place in the whole song using the spectrum in music structure and from the emotional aspect it can be divided into three sections: affectionate talk, inner battle and suffering, injustice and unyielding courage.

In the first paragraph, the prelude starts with slow and long tunes and the music material is from Ejiamei's main theme of the melody. From the lyrics "ancient mask flashes/ reminiscent of war and beacon/ where's my father's soul/ leaving what words hisdaughter did not know/ my fathers and brothers waded how much blood/ moisten the crops and lit the mountains", We could feel the sorrow and the tragic atmosphere. The music increased the use of small segmentation and by using the first eight and then sixteen and then weak start along with long tone and other rhythmic form accompanied by the wave of melody, it expresses the far-reaching worries and helpless talk of Ejiamei in "Fig. 1"

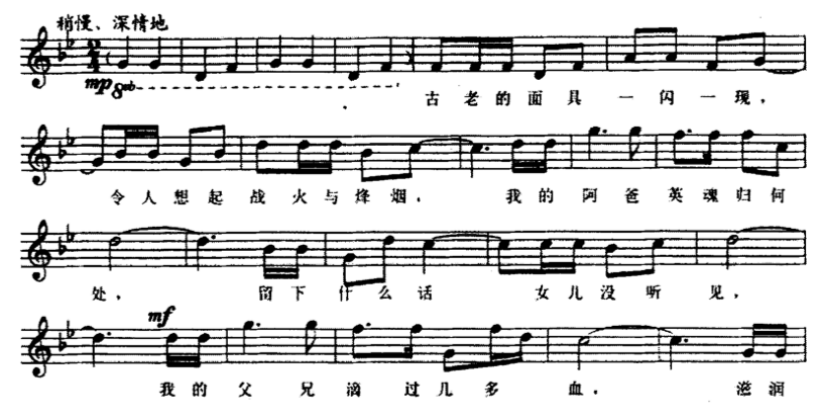

Fig. 1. Ejiamei's main theme of the melody.

Then, the melody goes into the middle of the song, which is made up by three phrases. In the first phrase: $25-33$ section, the melody becomes dense, accompanied by the texture of the chord into the chord, with the volume enhancement, the speed becomes faster, depicting the mood of Ejiamei in the face of the struggle between the two groups and her suffering from anxiety. In the second phrase: 34-54 section, the melody rushed to the highest point, with accompaniment mainly the arpeggios, then the music relaxed, making the emotional catharsis to reach the vertex, and then gradually fall back to the music in the low area.The ingenuity of music depicts Ejiamei's changing feelings from anxiety to inner talking very well in "Fig. 2".

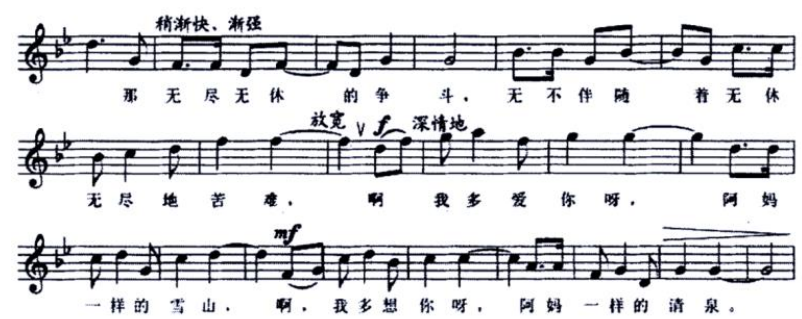

Fig. 2. The middle of Ejiamei's main theme of the melody.

2) Artistic Presentation of "Ejiamei"

The unique clothing of ethnic minority and brilliant, colorful form of performance are the main features of the play. Since "Ejiamei" was created according to the Sichuan Baima Tibetan classic story, its costume design is inseparable from the Tibetan people's style and charm. According to the plot and the background described, the concert opera "Ejiamei"'s costume design chooses Baima Tibetan clothing as the basis, coupled with the characteristics of new and smart to make it more adaptable tothe stage performance. Rich style, gorgeous colors and rich national flavor show the Baima and Dunbu peoples' folk customs and cultural characteristics and the original form of eco-clothing design add a unique feature to "Ejiamei".

In "Ejiamei," the choreography is also full of rich national characteristics for every part shows the "mood" as the theme with Chinese art style. The background of the story is in the northwest of the Baima cottage. The main features are rolling peaks typical of the North Sichuan landscape and white snow-capped mountains is the main symbol of the landscape in the northern part of Sichuan province. Therefore, in "Ejiamei", one of the elements made up of the background wall is the rolling peaks and white snow-capped mountains. "Feather" is a symbol of the Baima people's tribal soul and hope. White feathers floating in the layers of rolling hills, coupled with the use of brilliant light against the background and three-dimensional space structure, result in the whole beautiful, brilliant picture that fit the scene very well. The geographical style is shown on the stage perfectly. "Beauty is the perceptual appearance of ideas", is Hegel's famous argument. In the "Ejiamei" the stage fully explained out this argument.

\section{Artistic Achievements in "Ejiamei"}

The concert opera "Ejiamei" is not only a traditional repertoire with Sichuan characteristics, style, embodiment of Sichuan culture and its self-confidence; it is also a useful attempt to promote the exploration and innovation of art education in Sichuan Art Vocational College. It has far reaching influences on the practical art standards and requirements. The whole college from top to bottom has worked together to arrange the rehearsal, making this concert opera draw attention and finally get praises. In the summer of 2010, they made the first round of the show. In the autumn of 2011, the play appeared in the first Chinese opera festival and with its unique style, became the winner of three awards for outstanding repertoire. "Ejiamei", a concert opera composed by Sichuan Art Vocational College, as a concert 
opera created and performed by the college independently, add a unique page to the history of Chinese opera and at the same time provides an important example to the professional institutions of music teaching in China.

\section{CHINESE CONTEMPORARY OPERA PERFORMANCE: MARKET SURVEY}

To investigate the preferences of the contemporary domestic audience on the stage art, we need a relatively representative, quality control of the micro-data as a support, so this article uses the direct data collected through the website named Questionnaire Star. The sampling method adopted in this paper is a voluntary sample method for nonprobabilistic sampling. A total of 376 questionnaires were collected. According to the length of respondents' questions, 152 cases of invalid questionnaires and 224 valid questionnaires were included to meet the requirements of statistical sample size. The Questionnaires were distributed to social groups during the period from February to March 2017, with 376 responses and 224 valid questionnaires.

Through direct analysis of the results of the questionnaire, the author draws three main conclusions: First, in deciding whether to watch a repertoire, the audience hold the idea that "famous actor, famous director or screenwriter" and other objective reasons are not enough to constitute the reason that they watch the show. $42.41 \%$ of people think that the overall quality of the work is the main reason that attracts them to watch the show. Therefore, in the creation of works and rehearsals, under all allowed conditions at present, the focus should be on the quality of the work, enhance the integration of multi-disciplinary tools, ensure that the stage presentation quality as well as the script creation and meet the needs of the audience for high quality works down to earth. Second, $61.61 \%$ of people liked watching live performances compared to "TV broadcasts" and "Buy CDs" when asked about "watching form of the show", which indicates that the number of potential audience groups in China is very big. Thirdly, as to the reasons that make them away from the theater, we found that the "price is too high" accounted for a total of $74.45 \%$ of the total proportion. This shows that in the current theatrical performances, high fares are still the reason why those theatrical performances have always been "spring snow"(highbrow). The theater's failed popularity and publicity also hindered the audience's enthusiasm to walk into the theater.

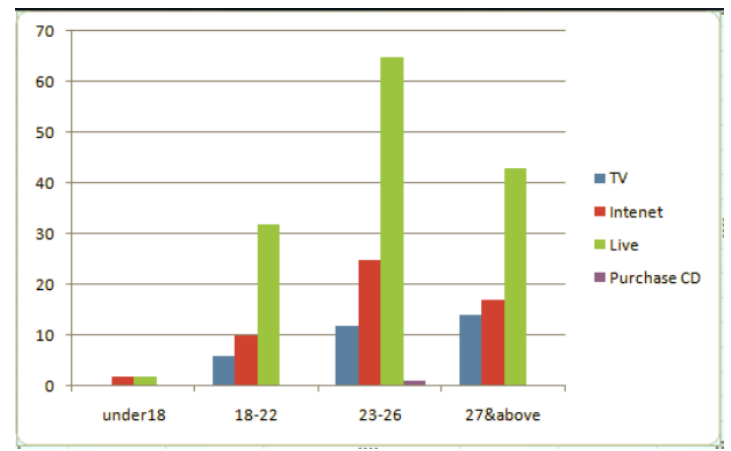

Fig. 3. Appreciation of different ages on theatrical performances
When doing cross analysis of "age" and "appreciation of the form of theatrical performances" as shown in "Fig. 3", it can be clearly seen that among the respondents over the age of 18 , whether it is an absolute number or a proportion, it is far more than any other form than viewing live performance by artists. Live performance has its unique charm as the questionnaire results show that the majority of the audience has strong demand for live literal performances.

Through the cross-analysis of "household per capita income" and "willing to spend per capita income in watching theatrical performances" as shown in "Fig. 4", it can be found that (the vertical comparison of different income stage of the respondents) from the quantitative point of view, most people choose $5 \%$ and $10 \%$ of the family per capita monthly income as the budget for watching theatrical performances, few people are willing to spend $15 \%$ and above the proportion of the budget as their consumer spending. Thus, here we can get to a very valuable conclusion: from the perspective of different income groups, $52.14 \%$ of the groups are willing to spend $5 \%$ of per capita income in watching theatrical performances, and according to the proportion of monthly income calculated, The current social public would like to spend $10 \%$ or less of family income in the performance and the specific value is 100 yuan to 400 yuan. This shows that with the improvement of social groups' living standards, literary and artistic consumption has become a necessity for everyone's life, which is important for the development of literary performance. However, through the specific questionnaire analysis and the current stage of the market performance of the show, it can be seen that the price of art performance is slightly higher than the audience expectations and there is still room for improvement in the pricing strategy. Thusto blindly pursue high fares, ignore the healthy market rules and the affordability of the audience is unwise.



Fig. 4. The vertical comparison of different income stage of the respondents

\section{CONCLUSION}

In recent years, the creation of Chinese opera has gone to an unprecedented height with the emergence of a number of outstanding opera works which firmly rooted in the foundation of traditional Chinese culture. These opera works have assimilated the national characteristics in their creative style and helped to contribute the formation of opera with Chinese characteristics. In the face of China's huge cultural 
performance market, the development of Chinese opera will also face more opportunities and challenges. The concert opera "Ejiamei", by Sichuan Art Vocational College, with its unique national characteristics, rich cultural connotation and practical art standards, add a rich and varied part to the history of contemporary Chinese opera.

\section{REFERENCES}

[1] Liu Yong. Music analysis of the concert opera "Ejiamei" [D]. Sichuan: Sichuan Normal University, 2013.

[2] JuQihong. Concert as its form, opera as its essence: a comment on the concert opera "Ejiamei" [D]. Sichuan: Sichuan drama, 2010.

[3] Lin Geer. On the Music Industry in the New Period of Higher Education [J]. Music Exploration. 2016 (03).

[4] Lin Geer. Brief introduction of Chinese opera [J]. Music Exploration. 2005 (01).

[5] Qian Yuan, Lin Hua. Introduction to opera [M]. Shanghai: Shanghai Music Publishing House, 2003.

[6] Ju Qihong, Ge Xiaoyi, etc. History of Chinese opera and musical theatre $[\mathrm{M}]$. Anhui; Anhui Literature and Art Publishing House, January 2014.

[7] Liu Qingsu, The Art of Musical Drama. [M]. Dunhuang: Dunhuang Literature and Art Publishing House, 2000. 